
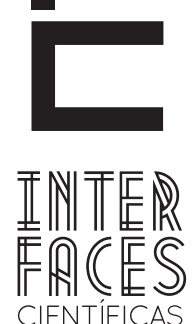

HUMANASE SOCIAIS

\title{
PROFISSIONALIZAÇ̃̃O, PROFISSIONALIDADE E SABERES DA EXPERIÊNCIA: PERSPECTIVA PARA FORMAÇÃO DO PROFESSOR
}

Maria José Oliveira Duboc ${ }^{1}$

\section{RESUMO}

Este artigo traz para o debate a formação do professor sob uma ótica que apesar de não ter sido incorporada no nosso meio, conta com uma vasta literatura que aponta para a especificidade do trabalho do professor, características do ofício de ensinar saberes de caráter prático, ou seja, saberes profissionais. Nessa perspectiva, realizou-se uma pesquisa empírica de caráter qualitativo, com professoras da educação básica da cidade de Feira de Santana, buscando responder as seguintes indagações: De que forma as professoras se manifestam diante da relação pro-
Solange Mary Moreira Santos ${ }^{2}$

fissão/profissionalidade? Quais os "saberes" que as professoras consideram necessários à profissão? Os dados coletados permitiram verificar o sentido que as professoras dão ao seu ofício e o confronto que realizam com os saberes necessários à sua atuação, oferecendo elementos para melhor entender as bases que sustentam a sua formação.

\section{PALAVRAS-CHAVE}

Profissionalidade. Saberes. Formação do Professor. 


\section{ABSTRACT}

This article brings to the debate teacher training under an optics that despite not having been incorporated in our midst has a vast literature that points to the specificity of the work of teachers, characteristics of the teaching knowledge of a practical character, or professional knowledge.In this perspective, we performed an empirical qualitative research study with teachers of basic education in the city of Feira de Santana, seeking to answer the following questions: How the teachers manifest themselves on the profession/professional relationship? What are the "knowledge" that the teachers consider necessary for the profession? The data collected allowed verifying the sense that teachers give to their craft and the confrontation that perform with the knowledge necessary for its activities, offering elements to better understand the foundations that support its formation.

\section{KEYWORDS}

Professionalism. Knowledge. Teachers Training.

\section{RESUMEN}

Este artículo trae a la discusión, la formación del profesor bajo una óptica que a pesar de no haber sido incorporado en nuestro medio, tiene una vasta literatura que apunta a la especificidad del trabajo del profesor, enseñando arte características de conocimiento de carácter práctico, es decir, profesionales de conocimiento. En esta perspectiva, una investigación empírica de carácter cualitativo, con los maestros de educación básica de la ciudad de Feira de Santana, tratando de contestar las siguientes preguntas: ¿Cómo los docentes se manifiestan en el componente de profesión y profesional? ¿Cuáles son los "conocimientos" que los profesores consideren necesarios para la profesión? Los datos recopilados permiten verificar el sentido de que los maestros dan a su oficio y la confrontación que realizan con el conocimiento necesario para sus actividades, ofreciendo elementos para comprender mejor los fundamentos que apoyan su formación.

\section{PALABRAS- CLAVE}

Profesionalidad. Conocimiento. Formación de profesores. 


\section{INTRODUCÃO}

Pesquisadores nacionais e internacionais, cada vez mais, vêm desenvolvendo estudos relacionados à profissão e à profissionalização de professor, na perspectiva de responder crítica e produtivamente aos desafios de formar indivíduos capazes de acompanhar as mudanças da informação e do conhecimento, que vêm sendo processadas de forma acelerada, na contemporaneidade. Essas mudanças têm causado alterações profundas na vida profissional do professor, que quase sempre se pautam no controle da profissão e no produto resultante da força de trabalho.

Nesse contexto, um ponto importante a ser considerado diz respeito à compreensão crítica dos processos pelos quais os professores, efetivamente, constroem sua própria formação, tornando-se relevante estudarmos a prática do professor, em relação aos saberes e aos conhecimentos que vão veiculando por meio de seu ensino.

Contudo, não podemos pensar o desenvolvimento profissional do professor dissociado das transformações ocorridas no mundo: sejam sociais, sejam econômicas, ou seja, políticas, as quais atingem as atividades docentes, por meio de demandas direcionadas à profissão. Para que tais demandas sejam respondidas é necessário que o professor compreenda a atividade social do seu campo de trabalho e tome sua formação, seus saberes e suas trocas sociais cotidianas como elementos de análise.

Essas ideias nos levam a considerar os rumos que vem tomando a sociedade, na qual os saberes científicos e tecnológicos são por demais valorizados e reservados aos seus autores um lugar social de destaque, secundarizando o conhecimento inscrito nas práticas reais, que a ciência teima em considerar irrelevante e ilusório com já nos alertava há 20 anos Boaventura de Souza Santos (1985). Esta ideia no campo educativo é efetivada pelo modelo e propostas pedagógicas oficiais que não dialogam e não consideram o saber, o fazer, o pensar que faz e vive o professor.

No entanto, autores como Contreras (2002), Perez Gómez (2001) Nóvoa (1995, 1997) Gimeno Sacristán (1995) Pimenta (1999) são representativos na análise das atividades comuns ao "estar sendo professor”. Isto é, além dos saberes científicos devem levar em conta o conjunto de comportamentos, conhecimentos, destrezas, atitudes e valores que propiciam referenciais para melhor compreender a base pedagógica da atividade profissional.

A partir dessas considerações, buscamos investigar a profissionalidade docente por meio dos saberes adquiridos na experiência que vão sendo construídos no exercício da prática docente. Consideramos esses elementos como fundamentais para a compreensão da profissionalidade e, consequentemente, do que se constitui ser professor.

Pretendemos, assim, focalizar, no processo de ensinar e aprender, os conhecimentos que vão sendo construídos e adquiridos pelo professor ao ensinar. Nessa perspectiva, formulamos as seguintes questões: De que forma as professoras se manifestam diante da relação profissão/profissionalidade? Quais os “saberes” que as professoras consideram necessários à profissão?

Neste trabalho, estamos discorrendo, de forma sintética a visão dos sujeitos da pesquisa e à luz de teóricos, que nos têm ajudado a tornar compreensíveis os conceitos com os quais trabalhamos: profissionalidade e saberes.

Consideramos oportuno destacar que o presente texto resulta do trabalho de pesquisa ${ }^{3}$ desenvolvido no Núcleo de Estudos e Pesquisa sobre Formação de Pro-

3. Este trabalho é um recorte da pesquisa do NUFOP intitulada: Profissionalidade docente: saberes e autonomia. 
fessores/NUFOP, na Universidade Estadual de Feira de Santana/UEFS, Bahia/Brasil, responsável pela realização de estudos que envolvem a temática "professores".

Nesta pesquisa, optamos pelo estudo de caso como abordagem metodológica. Os dados coletados nos permitiram chegar a algumas sínteses, que nos conduziram à sistematização de um processo reflexivo inerente à formação do professor, indicando elementos a serem considerados na organização dos cursos de licenciatura e do trabalho desenvolvido nas escolas, tendo em vista as condições de ser e estar na profissão.

\section{PROFISSÃO, PROFISSIONALIDADE E OFAZER DOCENTE}

Falar sobre profissão, profissionalidade e profissionalização docente requer necessariamente entender tais conceitos como temas visceralmente articulados, nos quais estão presentes convicções acerca do trabatho educativo, tendo em vista, principalmente, a complexidade e os desafios postos à atividade docente.

Os conflitos e a complexidade da docência justificam, de certa maneira, a discussão que se dá em torno da posição social que ocupa o professor, evidenciando a ambigüidade na vida do ser professor e da docência como sendo ou não profissão.

Cabrera e Jaén (1991), propondo-se em analisar a posição social da docência, ressaltam o conceito de profissão que a racionalidade técnica adota. Sob essa perspectiva, as profissões, de maneira geral, teriam características particulares que as distinguiriam como atividades necessárias, impondo-as diante de funções especialmente valorizadas. Demandariam aquisição de uma competência técnica específica, por meio de uma formação que socializaria o profissional num "código deontológico determinado" (CABRERA e JAÉN,1991, p.49). Nesse caso, o professor seria um especialista neutro, desempenhando seu trabalho via gerenciamento de técnicas de ensino, de organização escolar e de avaliação.
Em decorrência, a profissão docente vem sofrendo, visivelmente, um processo de crescente desprofissionalização e depreciação, principalmente na separação entre concepção e execução, padronização de tarefas, salários ínfimos e desvalorização de status, como lembram Tardif, Lessard e Lahaye (1991, p. 226):

\begin{abstract}
O corpo da igreja ou corpo do estado, o corpo docente parece ter permanecido um corpo de executantes [...]. Seu campo de intervenção se restringiu e sua competência diminuiu. 0 saber docente pluralizou-se e diferenciou-se com o surgimento de sub-grupos de especialistas. A idéia tradicional do docente como educador parece ultrapassada.
\end{abstract}

Chakur (2001) alerta-nos, também, para o fato de que nas sociedades se modificam ideais, valores e necessidades. Com isso, reconfiguram-se as exigências requeridas à educação institucionalizada e, assim, a profissão docente enfrenta, em certos momentos, a indefinição em suas funções.

Nesse sentido, Gimeno Sacristán (1998) assevera que a ação docente transcorre dentro de uma instituição que está inevitavelmente condicionada a fatores externos. Diz ainda que o professor não seleciona as condições nas quais realiza o seu trabalho e, muitas vezes, tão pouco escolhe como desenvolvê-lo, sofrendo, também, as múltiplas interferências exteriores e controles sobre o trabalho que desenvolve, até mesmo em sala da aula.

Evidencia-se a tendência à desprofissionalização da atividade docente, que parece ter-se acentuado nos últimos dez anos, principalmente em função da falta de confiança depositada, não apenas no trabalho do professor, mas na própria função da escola. Por conseguinte, afirmam Tardif, Lessard e Lahaye (1991, p. 226):

[...] os saberes transmitidos pela escola não parecem mais corresponder, senão de forma muito inadequada, aos saberes socialmente úteis (...). A escolarização, enquanto estratégia global que permite o acesso a funções sociais cobiçadas, não seriam mais suficientes. 
Contudo, a profissão docente tem certo prestígio por seu caráter intelectual ou artístico, pela posição social daqueles que a exercem, isto é, alguém competente, legítimo e remunerado por seus serviços e seus trabalhos (ALTET; PAQUAY; PERRENOUD, 2003). Assim, no exercício da profissão, ao profissional é exigido que aja com base nos conhecimentos disponíveis na sua formação acadêmica e nas regras de condutas adotadas pelo grupo no qual está inserido.

Dubar (1997, p. 34), citando Hughes, acrescenta, ao conceito de profissão, atributos fundamentais, quais sejam: o primeiro, o saber profissional, "que está no cerne da profissão e que se trata de um segredo social confiado pela autoridade a um grupo específico, que autoriza o mandato para trocar sinais de transgressão pelas marcas de reintegração social e de reabilitação moral"; e o segundo atributo "é a existência de instituições destinadas a proteger o diploma e a manter o mandato dos seus membros".

Assim, na profissão apreende a categorização de ofício, de ocupação ou de emprego, requerendo domínios de campos especializados com forte ligação à prestação de serviços. Esses serviços devem relacionar-se sempre a um grupo social, regulado por princípios éticos e por códigos específicos que controlem, explicitem e sistematizem os saberes adquiridos e desenvolvidos em conhecimento e em formação (PESSANHA, 1994).

A profissionalização, por sua vez, é um conceito utilizado em sentidos diferentes, a depender do contexto em que está sendo empregado. Altet, Perrenoud e Paquay (2003) asseguram que esse termo é um conceito plurívoco, indicando que no dicionário de Robert, ano de 1985, significa a ação de profissionalizar, de tornar-se uma profissão. Esses autores, citando G. Jobert, afirmam que a profissionalização recobre dois processos relacionados, a saber:
[...] o primeiro como "desenvolvimento de competências", corresponde ao aspecto mais conhecido do processo; o segundo como "luta social de um grupo profissional", é menos evocado. Esses processos complexos desenvolvem-se em uma interação constante entre dimensões epistêmicas e praxeológicas (saberes próprios ao grupo, ligados às situações profissionais) e dimensões sociais de reconhecimento do grupo profissional. (ALTET; PERRENOUD; PAQUAY, 2003, p. 236).

A profissionalização depende, entre muitos fatores, de como compreendemos e analisamos as práticas educativas; como articulamos saberes da docência no ato de ensinar; como refletimos na ação, diante do inesperado, do desconhecido, que constitui grande parte de atividade docente; e como refletimos, na prática educativa distanciada do dia a dia, a busca por novas possibilidades de agir no ensino. Como desenvolvimento sistemático da profissão, a profissionalização busca subsídios "na prática e na mobilização/atualização de conhecimentos especializados e no aperfeiçoamento das competências para atividade profissional" (RAMALHO; NUÑEZ; GAUTHIER, 2003, p. 50).

Desse modo, a profissionalização deve ser vista a partir da especificidade do trabalho do professor, na situação de profissionalidade, uma vez que este desempenha condutas que são conformadas por meio das relações profissionais, sociais, afetivas culturais estabelecidos no espaço em que atua.

A expressão profissionalidade, sob determinados aspectos, carrega marcas de natureza abstrata e se aproxima de uma visão filosófica, quando aponta para uma concepção que faz separação entre a qualidade a ser desenvolvida e o objeto. Os elementos que compõem a profissionalidade como: as habilidades, as destrezas e os conhecimentos estão no sujeito (profissional) que as descobre e não na relação entre o sujeito e objeto. Entende-se por objeto, grosso modo, o desenvolvimento do ensino. De fato, se existe uma separação entre as qualidades (requisitos) do profissional e a realidade imposta ao ensino, então, como se efetiva eficazmente o fazer docente? Qual é esse saber-fazer? 
Do ponto de vista de Contreras (2002, p. 74), a profissionalidade se refere: "[...] às qualidades da prática profissional dos professores em função daquilo do que requer o trabalho educativo [...]". Nesse sentido, profissionalidade refere-se ao desempenho do ofício de ensinar, mas também expressa valores, intenções que se quer alcançar e desenvolver na profissão.

Figura I - Elementos da Profissionalidade

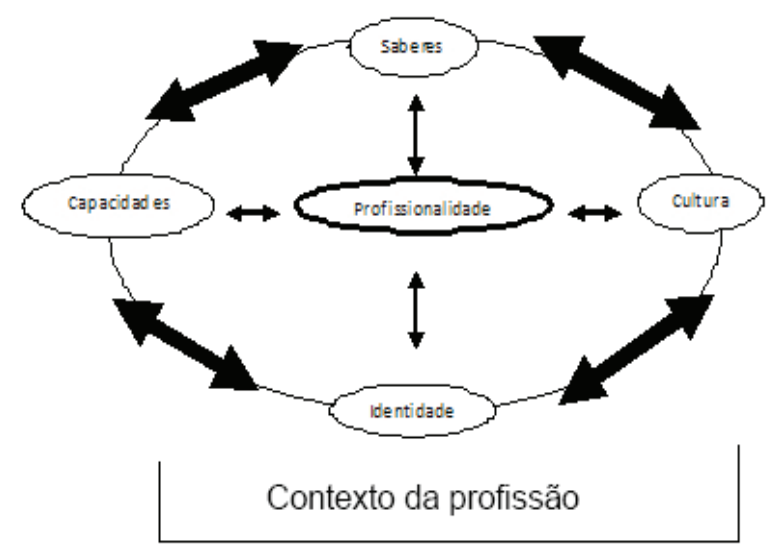

Quando a profissionalidade se estabelece como um "ideal" da profissão, não se materializando na prática, reforça a mitificação da não relação entre teoria e prática, da impossibilidade de ação-reflexão-ação, da reflexividade. Estabelece, assim, a sensação de impotência e incapacidade, hoje muitas vezes associada ao profissional docente. Nesse contexto, a abstração mais aceitável é aquela que caracteriza as qualidades da profissionalidade como identificação do profissional, sua capacidade de adaptar-se às condições e às necessidades de determinado tempo, espaço e sociedade, o que cria uma diversidade do saber-fazer, na unidade "do ser professor" (DOMINGUES, 2004).

Esse entendimento é ampliado por Cunha (1999), quando apresenta a profissionalidade como profissão em ação, interpretando-a como "a possibilidade de construção coletiva do pro- fessor e seus alunos, em que interagem subjetividade, cultura e conhecimento" (1999, p. 135). Essa construção, portanto, está condicionada às questões sociais, econômicas e históricas, que envolvem o exercício da profissão, cujos saberes só podem ser compreendidos, quando relacionados às condições de trabalho.

A profissionalidade constitui-se pela autonomia que o docente exerce na escola, diante de seu trabalho; pela responsabilidade com sua própria formação permanente; pela capacidade de aprender e de refletir sobre sua ação; pelo entendimento de que, ao se tornar profissional, também passou a significar "ser competente".

Esses aspectos legitimam a nossa reflexão sobre a profissionalidade que, segundo Altet, Perrenoud e Paquay (2003), pode ser definida em termos de funções específicas a assumir e de competências a aplicar, mas, também, em termos de identidade e de questões sociais. Para esses autores, a profissionalidade seria "o conjunto de competências que um profissional deveria ter ou, ainda, o conjunto de competência reconhecida socialmente como característica de uma profissão" (ALTET, PERRENOUD e PAQUAY, 2003, p. 235).

Diante do inesperado, ele age com seu "talento artístico", fazendo uso de seu reservatório de conhecimentos, mobilizando seus saberes, conforme exige a situação particular, ou mesmo, procurando adquirir novos conhecimentos, impulsionando sua autoformação. 0 professor exerce sua própria prática, a partir de valores, de princípios, de convicções éticas e políticas.

Assim, o desafio da sua profissionalização está na compreensão de "um ofício feito de saberes" ${ }^{\text {, no qual }}$ se entrelaçam: aspectos pessoais (os próprios compromissos profissionais) com os relacionamentos (já que o

4. Esses saberes se referem a: saber disciplinar, saber curricular, saber das ciências da educação, saber da tradição pedagógica, saber experiencial e saber da ação pedagógica. 
ensino se realiza sempre em contexto de relações pessoais e sociais); tentativas de compreensão e de equilíbrio social com a defesa de valores e a independência de juízo com a participação.

\section{A CONSTRUÇÃO DA PROFISSIONALIDADE DAS PROFESSORAS}

No percurso profissional das professoras, consideramos o que contaram sobre a profissão, buscando localizar a importância da sua profissionalidade.

Nessa análise, a profissionalidade é concebida como uma determinada maneira de se fazer do profissional, que se distingue, se recorta de outras maneiras de fazer, típicas da pessoa comum ou, como afirma Contreras (2002), são as qualidades necessárias ao próprio trabalho de ensinar.

Contreras (2002) analisa três dimensões da profissionalidade numa perspectiva educativa:

I. A obrigação moral. Esta primeira dimensão é derivada do fato de que o ensino supõe um compromisso de caráter moral para quem o realiza.

II. O compromisso com a comunidade. Esta segunda dimensão é derivada da relação com a comunidade social, na qual os professores devem realizar a prática profissional. Para Contreras (2002), a educação não é um problema da vida privada do professor, mas uma ocupação socialmente encomendada e responsabilizada publicamente.

III. A competência profissional. A obrigação moral dos professores e o compromisso com a comunidade requerem uma competência profissional coerente com ambos. Segundo Contreras (2002), há que se falar de competências profissionais complexas, que combinam habilidades, princípios e consciência do sentido e das consequências das práticas pedagógicas.
Esses aspectos constituem, pois, a subjetividade profissional traduzida como experiências apreendidas e acionadas no cotidiano escolar. É um 'saber fazer' construído individualmente, a partir de referenciais externos, porém que se tornam próprios e únicos. São instrumentos construídos pelo próprio professor, para deles se utilizar na profissão, tornando-os um saber pessoal. Esse saber não se refere somente à prática, mas, também, à maneira de posicionar-se diante da profissão, de entendê-la na interação e como contribuição social, ética e política.

Nessa direção, instala-se o pensamento de Perez Gómez (2001) afirmando ser a profissionalidade um processo de ação e de reflexão cooperativa, de indagação e de experimentação, no qual o professor aprende ao ensinar e ensina porque aprende, intervém para facilitar e não para impor e nem substituir a compreensão dos alunos. Além disso, ao refletir sobre sua intervenção, o professor desenvolve sua própria compreensão do trabalho que exerce.

Ao lançarmos um olhar mais detido e mais arguto sobre as professoras, foi possível reavaliar a vida profissional, imprimindo novos significados à experiência vivida e estabelecer perspectivas para a formação.

Desse modo, ao ouvir cada professora, fomos colhendo pistas para esse trabalho, no sentido de entender as necessidades que o exercício profissional requer cotidianamente. Assim, a partir das informações obtidas, procuramos encontrar indícios que pudessem revelar a relação da profissão e profissionalidade.

As professoras pesquisadas evidenciam uma imagem da profissão afetiva e prazerosa, contraditoriamente marcada pela falta de reconhecimento da sociedade principalmente do poder público. $\mathrm{Na}$ opinião de Contreras (2002, p. 209), essa visão popular da profissionalidade é um aspecto que tem sido proibido, pois: 
ser profissional tem sido encarado como ter a capacidade de distanciamento afetivo das situações e pessoas com as quais se trabalha, como não-envolvimento. Desta perspectiva de especialista técnico, os sentimentos são inclusive um inconveniente que pode alterar o diagnóstico ou a aplicação racional dos métodos de ensino.

Vimos, também, que o respeito ao aluno, como pessoa e como sujeito da própria aprendizagem, marca a fala das professoras que revelam preocupação com a valorização do conhecimento do aluno e com o processo de crescimento de cada um deles, durante as atividades letivas e ao mesmo tempo, não deixam de lado cumprir o estabelecido no programa oficial.

Assim, no cotidiano escolar são configurados os dilemas práticos/teóricos, aos quais as professoras procuram dar respostas por meio de um saber mais consistente, mais adequado à atuação. Para tanto, buscam várias fontes orientadoras do processo de ensino e de aprendizagem. A esse respeito, Guimarães $(2004$, p. 49) ressalta que essa "é uma profissão que implica saberes e que um processo formativo conseqüente demanda compreender como esses saberes são produzidos, integrados e utilizados na prática profissional".

As professoras retratam demandas da profissão docente que mudam em virtude da historicidade e da contextualização e como tal, exige novos mecanismos para a formação. Diante desse quadro, elas destacam a necessidade de melhor fazer e recorrem ao trabalho coletivo como elemento de transformação, pois congrega esforços de atualização o que é uma constante na escola.

A inquietação das professoras com a própria formação, na perspectiva de Ramalho, Nuñez e Gautier (2003, p. 41) significa "uma sincronia entre a formação inicial e continuada como um sistema coerente e articulado".

No entanto, há uma difícil comunicação entre a formação acadêmica e o que se dá na escola, expresso nas falas contraditórias das professoras que ora valorizam uma em detrimento de outra, conforme as situações concretas vividas em sala de aula.

\section{FORMAÇÃO E SABERES NO EXERCÍCIO DA PROFISSÃO}

Estudos desenvolvidos por Tardif (2002) vêm apontando a relevância da formação ${ }^{5}$ e da produção dos saberes, evidenciando a relação entre formação e o exercício da profissão, mostrando que o professor mobiliza saberes profissionais que são construídos e reconstruídos, conforme a necessidade e que precisam ser conhecidos, sistematizados e valorizados. Cabe-nos, então, perguntar: qual saber é mobilizado pelos professores em sua ação pedagógica? Tal saber pode ser consumido e, também, produzido pelos professores?

Em relação aos saberes que integram a prática docente, Tardif Lessard e Lahaye (1991, p. 218) definem como plurais por serem oriundos da formação profissional, das disciplinas, dos currículos e da experiência. Consideram por saberes da formação profissional, o conjunto de saberes provenientes das ciências da educação e transmitidos institucionalmente na formação docente. Incluem-se, nesse conjunto, os saberes pedagógicos, responsáveis tanto pelas orientações ideológicas da atividade educativa (doutrinas, sistemas), como pela transmissão de técnicas e formas de saber fazer.

Os saberes das disciplinas correspondentes aos vários campos de conhecimentos são tradicionalmente transmitidos em forma de disciplinas, nas universidades. Os saberes curriculares referem-se aos discursos, objetivos, conteúdos e métodos que professores devem aprender e aplicar na forma de programas escolares.

5. 0 entendimento de formação aqui adotado considera, também, que as experiências e os cursos de formação vão ter influência na formação docente. Como bem expressa Nóvoa (1992), a formação é um ciclo que abrange a experiência como aluno e prossegue por todo o exercício profissional. 
Quadro 1 - A constituição dos saberes dos professores

\begin{tabular}{|l|l|l|}
\hline \multicolumn{1}{|c|}{ Saberes dos Professores } & \multicolumn{1}{|c|}{ Fontes sociais de aquisição } & \multicolumn{1}{c|}{$\begin{array}{c}\text { Modos de integração no } \\
\text { trabalho docente }\end{array}$} \\
\hline Saberes pessoais dos professores & $\begin{array}{l}\text { A família, o ambiente de vida, a edu- } \\
\text { cação no sentido lato, etc. }\end{array}$ & $\begin{array}{l}\text { Pela história de vida e pela socializa- } \\
\text { ção primária. }\end{array}$ \\
\hline $\begin{array}{l}\text { Saberes provenientes da forma- } \\
\text { ção escolar anterior }\end{array}$ & $\begin{array}{l}\text { A escola primária e secundária, os } \\
\text { estudos pós-secundários não espe- } \\
\text { cializados, etc. }\end{array}$ & $\begin{array}{l}\text { Pela formação e pela socialização pré- } \\
\text {-profissionais. }\end{array}$ \\
\hline $\begin{array}{l}\text { Saberes provenientes da forma- } \\
\text { ção profissional para o magistério }\end{array}$ & $\begin{array}{l}\text { Os estabelecimentos de formação de } \\
\text { professores, os estágios, os cursos de } \\
\text { reciclagem etc. }\end{array}$ & $\begin{array}{l}\text { Pela formação e pela socialização pro- } \\
\text { fissionais nas instituições de formação } \\
\text { de professores. }\end{array}$ \\
\hline $\begin{array}{l}\text { Saberes provenientes dos pro- } \\
\text { gramas e livros didáticos usados } \\
\text { no trabalho }\end{array}$ & $\begin{array}{l}\text { A utilização das 'ferramentas' dos pro- } \\
\text { fessores: programas, livros didáticos, } \\
\text { cadernos de exercícios, fichas, etc. }\end{array}$ & $\begin{array}{l}\text { Pela utilização das 'ferramentas' de } \\
\text { trabalho, sua adaptação às tarefas. }\end{array}$ \\
\hline $\begin{array}{l}\text { Saberes provenientes de sua pró- } \\
\text { pria experiência na profissão, na } \\
\text { sala de aula e na escola. }\end{array}$ & $\begin{array}{l}\text { A prática do ofício na escola e na salala } \\
\text { de aula, a experiência dos pares, etc. }\end{array}$ & $\begin{array}{l}\text { Pela prática do trabalho e pela sociali- } \\
\text { zação profissional. }\end{array}$ \\
\hline
\end{tabular}

Fonte: Tardif (2002, p. 63).

Os saberes da experiência, enfim, são aqueles desenvolvidos pelos próprios professores, em sua prática profissional, baseados "em seu trabalho cotidiano e no conhecimento de seu meio. Esses saberes brotam da experiência, são por ela validados e se incorporam à experiência individual e coletiva sob a forma de habitus e de habilidades, de saber fazer e de saber ser" (TARDIF, 2002, p. 39).

Tardif (2002) ressalta que os professores têm uma relação de exterioridade com esses primeiros saberes, que são ecléticos e sincréticos ${ }^{6}$. Diz que eles por não se apoiarem em uma única teoria lançam mão de muitas teorias e concepções, conforme a necessidade; e que são personalizados, pois suas ações carregam marcas dos contextos nos quais vão se inserindo.
Afirma, ainda que, nas profissões de interação humana, a personalidade é absorvida no processo de trabalho. Nesse sentido, o referido estudioso enfatiza, também, a importância dos saberes da experiência, considerando-os como núcleo básico do saber docente, que se integra à prática e como parte constituinte dela, pois "os saberes da experiência não são como os demais saberes, são, ao contrário, formados de todos os demais saberes, mas retraduzidos, "polidos" e submetidos às certezas construídas na prática e na experiência” (TARDIF, 2002, p. 54).

No quadro a cima, Tardif (2002, p. 63) identifica e classifica a constituição dos saberes dos professores:

6. São considerados saberes ecléticos e sincréticos a cultura pessoal, história de vida e a cultura escolar anterior; conhecimentos adquiridos na universidade; conhecimentos curriculares, entre outros. 
Em relação aos saberes da experiência, Therrien (apud TARDIF, LESSARD e LAHAYE, 1998), os caracteriza por serem originados na prática cotidiana da profissão, sendo validados pela mesma podem refletir tanto a dimensão da razão instrumental que implica num saber-fazer ou saber-agir tais como habilidades e técnicas que orientam a postura do sujeito, como a dimensão da razão interativa que permite supor, julgar, decidir, modificar e adaptar, de acordo com os condicionamentos de situações complexas.

\section{OS SABERES DA EXPERIÊNCIA DAS PROFESSORAS}

Na visão de Ramalho, Nuñez e Gauthier (2003, p. 29-30) os saberes da experiência "têm um caráter prático, com características diferentes dos conhecimentos que emergem da pesquisa acadêmica”, são saberes profissionais, com nível de teorização ligado a contextos específicos. Segundo esses autores, excetuando os saberes da experiência, todos os demais se secundarizam uma vez que são incorporados à prática docente, sem que tenham sido aí produzidos e legitimados. Por exemplo, as professoras, de forma geral, se referem à formação acadêmica como válida, mas reconhecem que a formação não dá conta da complexidade da prática docente.

A literatura consultada ressalta que o conhecimento implementado na prática, passa por um processo de apropriação e de transformação, que nunca é uma simples cópia da ideia original, mas uma reconstrução entre os significados e saberes da professora diante do que a situação lhe sugere. É preciso, pois, não controlar a definição dos saberes curriculares e disciplinares e nem mesmo os saberes pedagógicos transmitidos nas instituições de formação. Os professores seriam, então, apenas consumidores de saberes? E o que dizer dos saberes da experiência?
Os saberes da experiência, como denominam Tardif, Lessard e Lahaye (1991), não são sistematizados nem organizados pela teoria tal como as percebemos. A esse respeito, Tardif (2002, p. 49) assevera: “os saberes práticos e não da prática: eles não se aplicam à prática para melhor conhecê-la, eles se integram a ela e são partes constituintes dela enquanto prática".

Ainda segundo Tardif, Lessard e Lahaye (1991), os saberes da experiência possuem três objetos/ condições: relações e interações que os professores estabelecem com os demais agentes, em seu campo de atuação; normas e obrigações que regulam o trabalho docente; e o meio institucional no qual atuam os professores. Tais saberes são adquiridos, especialmente, no início da carreira ${ }^{7}$, mas essa experiência inicial tende a fixar-se num estilo pessoal de ensinar, em macetes da profissão, em habitus, em traços da personalidade profissional. Além disso, esses saberes são hierarquizados, em função das dificuldades que trazem para a prática. Então, saber relacionar-se com os alunos, por exemplo, torna-se mais importante que saber relacionar-se com os especialistas.

Nessa perspectiva, os saberes da experiência docente adquirem certa objetividade e, à medida que são transmitidos nas relações entre pares, estabelecem um confronto entre saberes produzidos pelo coletivo de professores, momento em que os professores são levados a tomar consciência de seus próprios saberes da experiência.

0 trabalho docente resulta, assim, em um conjunto de interações entre colegas, que têm participação efetiva no processo de formação, visando a atender às diferentes necessidades do cotidiano. Há certa

7. O desenvolvimento de uma carreira é, assim, um processo e não uma série de acontecimentos. Para alguns, este processo pode parecer linear, mas, para outro, há patamares, regressões, becos sem saídas, momentos de arranque, de descontinuidade. Trata-se de ouvir o que o professor tem a dizer, respeitar e tratar rigorosamente os dados que o professor introduz nas narrativas e que vêm alterar o equilíbrio comparativo. 
complexidade nos saberes docentes, decorrente do seu caráter plural. É interessante observar que Tardif, Lessard e Lahaye (1991), analisando esses saberes, buscam superar o modelo da racionalidade técnica, chamando a atenção para a existência dos saberes da experiência, que não são "para" e "sim" da prática.

Deduzimos que o saber da experiência articula e reorganiza os demais, que mostra a diversidade de sua constituição, evidenciando a relação dos saberes da prática com os demais. No entanto, ao destacar os saberes que surgem na experiência, os autores indicam a possibilidade de o professor "transformar as relações de exterioridade com os saberes, em relações de interioridade com sua própria prática (TARDIF, 2002, p. 54)”. Esses saberes, oriundos da prática, podem ser reconhecidos e adotados por outros grupos sobre os quais se poderia reivindicar um controle social legítimo.

Nessa situação, o professor vai construindo um conhecimento prático, um "tipo particular de informação e aprendizagens que a prática proporciona e que se vão consolidando como um autêntico corpo de conhecimentos, a partir do qual os professores descrevem e justificam a sua ação" (ZABALZA, 1994, p. 51).

Tardif (2002), por sua vez, considera que o saber é a marca do professor que se realiza por meio de experiências anteriores e atuais, em diferentes níveis. É uma realização pessoal partilhada no coletivo, no contexto da socialização profissional. Considera o saber dos professores um processo em construção, no decorrer da trajetória profissional, uma vez que o professor aprende ao dominar e se inserir no seu ambiente de trabalho; aprende, também, por meio de regras de ação; aprende ao interiorizar um saber que, na dinâmica construtiva da prática, representa parte essencial deste saber.

O professor assim, no exercício da profissão, mobiliza, articula e organiza saberes, de forma intersectiva, conforme ilustra a figura II abaixo.
Figura II - Saberes Pedagógicos

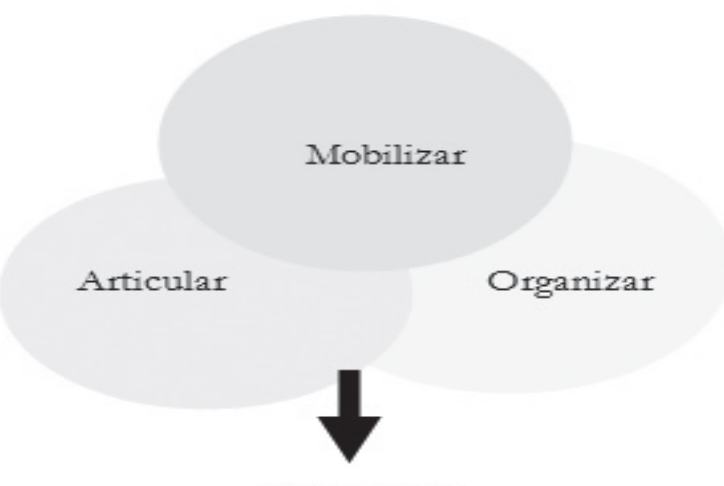

SABERES

As características da figura anterior tornam-se importantes diante das seguintes falas das professoras: "o professor tem que ser pesquisador, criativo, buscar remediar qualquer situação inesperada que acontece na sala de aula". "Os professores têm que dominar os conteúdos que vão trabalhar em classe, os projetos que estão trabalhando, enfim precisam estudar para fundamentar sua prática".

Os extratos acima demonstram que as professoras valorizam os saberes acadêmicos e dão destaque ao fato de reconstruírem os saberes científicos, disciplinares nas experiências, embora não valorizem devidamente tal feito.

A literatura consultada ressalta que os fundamentos do saber ensinar não se reduzem a único saber, porque eles são plurais. Eles se esboçam na epistemologia da prática, num processo interativo, representados pela história, personalidade, recursos e limites do profissional, que tem pouca relação com os modelos de conhecimento técnico. E que a construção do saber pedagógico ocorre a partir dos conhecimentos apreendidos do contexto social e ressignificados como aprendizagem individual de cada professora que não é reconhecido e valorizado e acabam refletindo na prática. 


\section{CONSIDERAÇÕES FINAIS}

Nessa análise sobre profissão, profissionalidade e saberes adquiridos no exercício da prática, tendo como suporte as reflexões teóricas apresentadas, procuramos compreender as diferentes circunstâncias que constituem a realidade de ser da professora envolvida na pesquisa.

Dessa forma, destacamos alguns pontos que emergiram da investigação:

- As professoras, preocupadas diante da complexidade do trabalho que exercem, buscam na formação acadêmica encontrar alternativas para dar conta das dificuldades da profissão;

- Há um investimento na formação continuada dos professores no interior da escola, mas dissociado das questões que vivenciam no dia a dia;

- Contraditoriamente as nossas protagonistas, embora valorizem a formação acadêmica, na prática, têm dificuldade de evocar a teoria e, então, se valem da experiência para dar conta do processo ensino-aprendizagem;

- Comumente as professoras lançam-se em busca de um suporte, para dar conta dos problemas que enfrentam, seja de forma isolada, recorrendo ao colega, ou ainda solicitando apoio da coordenação;

- Na prática das professoras, há um saber significativo, que não é reconhecido.

Essas indicações evidenciam a importância de uma revisão na formação do professor, com base na articulação prática-teoria-prática, para a construção de um paradigma que traga para os cursos de formação a presença complexa do cotidiano dessa profissão. Os resultados dessa investigação demonstram a necessidade de se investir melhor nos saberes desenvolvidos no cotidiano da sala de aula, uma vez que a profissio- nalização depende, entre muitos fatores, de como compreendemos e articulamos saberes da docência no ato de ensinar, como refletimos na ação, diante do inesperado, que constitui grande parte de atividade docente;

\section{REFERÊNCIAS}

ALTET, PAQUAY, L. \& PERRENOUD, Ph. A profissionalização dos formadores de professores: realidade emergente ou fantasia? In: ALTET, PAQUAY, L. \& PERRENOUD, Ph. (Org) A profissionalização dos formadores de professores. Porto Alegre: Artmed, 2003.

CABRERA, B.; JÁEN, M. J. Quem são e que fazem os docentes? Sobre o conhecimento sociológico do professorado. Teoria e Educação, n.4. Porto Alegre, 1991.

CHAKUR, Ciliene R. de Sá Leite. Desenvolvimento profissional docente: contribuições de uma leitura piagetiana. Araraquara: JM, 2001.

CONTRERAS, J. D. A autonomia de professores. São Paulo: Cortez, 2002.

CUNHA, Maria Isabel da. Profissionalização docente: contradições e perspectivas. In: PASSOS, Ilma Veiga; CUNHA, Maria Isabel da. Desmistificando a profissionalização docente. Campinas, SP: Papirus, 1999.

DOMINGUES, Isaneide. A profissionalidade docente: a (re)construção da profissão na escola. Anais do XII ENDIPE. Curitiba, 2004.

DUBAR, C. A socialização: construção das identidades sociais e profissionais. Porto-Portugal: Porto, 1997.

GIMENO SACRISTÁN, J. Consciência e ação sobre a prática como libertação profissional dos professores. In: NÓVOA, António. (Org.) Profissão professor. Porto: Publicações Dom Quixote/IIE, 1995. 
GIMENO SACRISTÁN, J. ; PÉREZ GÓMES, A I. Compreender e transformar o ensino. Porto Alegre: Artes Médicas, 1998.

GUIMARÃES, Valter Soares. Formação de professores: saberes, identidade e profissão. Campinas: Papirus, 2004.

NÓVOA, Antônio. Formação de professores e profissão docente. In: NÒVOA A (org) Os professores e a sua formação. Lisboa: Dom Quixote, 1997.

NÓVOA, Antônio. O passado e o presente dos professores. In: NÓVOA, António. (Org.) Profissão professor. Porto: Dom Quixote, 1995.

PEREZ GÓMEZ, A. I. A cultura escolar na sociedade neoliberal. Porto Alegre: Artemed, 2001.

PESSANHA, E. C. Ascensão e queda do professor. São Pauo: Cortez, 1994.
PIMENTA, Selma Garrido. Formação de professores: identidade e saberes da docência. In: PIMENTA, Selma Garrido (Org.) Saberes pedagógicos e atividade docente. São Paulo: Cortez, 1999.

RAMALHO, Betania Leite; NUÑEZ, Isauro Beltrán; GAUTHIER, Clermont. Formar o professor profissionalizar o ensino: perspectivas e desafios. Porto Alegre: Sulina, 2003.

SANTOS, Boaventura de Souza. Um discurso sobre as ciências. Porto: Afrontamento, 1985.

TARDIF, M; LESSARD, C; LAHAYE, L. Os professores face ao saber: esboço de uma problemática do saber docente. Teoria e educação, Porto Alegre, n.4, 1991.

TARDIF, Maurice, Saberes docentes e formação profissional. Petrópolis-RJ: Vozes, 2002.

ZABALZA, M. A. Diários de aula (contributo para o estudo dos dilemas práticos dos professores). Porto: Porto, 1994.

\footnotetext{
1. Mestre em Educação Especial, CEEALE/Cuba. Professora Assistente da Universidade Estadual de Feira de Santana/UEFS. E-mail: mariaduboc@ig.com.br.

2. Doutora em Educação - Currículo, pela PUC/SP. Professora Adjunta da Universidade Estadual de Feira de Santana/UEFS. E-mail: solange. santos@ig.com.br
} 